\title{
"Global" Productivity Trends, Consumption Expenditures and US Macroeconomic Conditions: A Verification of the "Contagion" Phenomenon
}

\author{
Rexford Abaidoo ${ }^{1}$ \\ ${ }^{1}$ School of Business and Technology, University of Maryland Eastern Shore, USA \\ Correspondence: Rexford Abaidoo, School of Business and Technology, University of Maryland Eastern Shore, \\ USA.E-mail: rabaidoo@umes.edu
}

Received: February 23, 2015

Accepted: March 10, 2015

Online Published: April 25, 2015

doi:10.5539/ibr.v8n5p55

URL: http://dx.doi.org/10.5539/ibr.v8n5p55

\begin{abstract}
Panel discussions on global economic performance and the role of economic shocks, often creates the notion that adverse macroeconomic conditions prevailing in dominant economies such as the U.S, tend to have automatic impact on domestic conditions of other economies around the world. This study examined this perceived automatic contagion phenomenon by verifying how key modeled adverse macroeconomic conditions characterizing the U.S economy influence two macroeconomic indicators within selected advanced economies. Empirical estimation via SUR estimation technique verified this contagion phenomenon to some degree; test results suggests adverse macroeconomic conditions such as economic policy uncertainty, inflation expectations etc. can influence core economic indicators within some economies around the world. This study however, also found that not all cross-border interactions exhibits features of the contagion phenomenon, because some economies examined seem to be relatively insulated from modeled cross-border macroeconomic conditions.
\end{abstract}

Keywords: contagion phenomenon, adverse macroeconomic conditions, SUR, advanced economies

\section{Introduction}

Do occasional adverse macroeconomic conditions or challenges in the U.S economy automatically influence key domestic macroeconomic indicators or conditions within other economies around the world? If so, do such conditions constrain growth or rather creates economic opportunities within these external economies due to growing integration as some have argued? These questions, spurred by growing divergent views on how macroeconomic conditions within a dominant economy like the U.S impacts domestic economic conditions of other economies around the world, defines the rational for this study. Related literature on similar relationship provides significant body of empirical work suggesting some relationship between macroeconomic conditions in one economy and performance of economic indicators in other economies. For instance, the concept of "Uncertainty Channel of Contagion" propounded by Kannan and Kohler-Geib (2009), which is an expansion of earlier concepts on cross-border macroeconomic interactions; to a greater extent, revolves around the notion of cross-border impact of macroeconomic conditions. In their study of the relationship in question, Kannan and Kohler-Geib (2009) sought to outline mechanics explaining how "crisis" in one economy impacts decision making behaviors among economic agents in other economies; ultimately influencing the probability of economic crisis or otherwise in those economies. Despite existing empirical and recent evidences of economic "contagion" effects (As evidenced in how recent recession (2007) emanating from the U.S impacted economies around the world), there is still an ongoing academic discussions on whether macroeconomic conditions in a dominant economy such as the U.S automatically influence economic activities around the world. Significantly constrained growth of the US economy in recent years and its perceived impact on the global economy as a whole, continue to add to this growing debate on automatic cross-border macroeconomic interactions.

Fundamental questions raised above, on how key economic indicators among economies around the world might responds to adverse or otherwise macroeconomic conditions emanating from the US economy forms the basis of this study's enquiry. This paper among other things, specifically examines the extent to which domestic macroeconomic conditions among key advanced economies around the world responds to adverse macroeconomic conditions in the US economy, in order to verify growing perception of waning US economic 
influence, and its impact on global economic performance. Additionally, this study also seeks to test the presumption that adverse US macroeconomic conditions might not necessarily constrain growth of specific macro-indicators among key economies around the world as often believed due to the potential for moderating domestic policies or economic conditions. To examine this economic contagion effect phenomenon, this study employs three "adverse" macroeconomic conditions modeled as a feature characterizing the U.S economy; and estimate how industrial productivity and domestic private consumption expenditures among six selected advanced economies around the world react to such macroeconomic conditions. The choice of industrial productivity and private final consumption expenditure as a measure of macroeconomic performance within selected economies to be tested is based on the fact that much of the variability in GDP growth (a measure of general economic performance) can be attributed to consumption expenditure dynamics and industrial productivity.

As alluded to earlier, the view that macroeconomic 'events' or adverse macroeconomic conditions tend to have some measure of cross-economy impact is not new to the macroeconomic literature. Studies such as Kamau (2010), Naveh, M. H., Toros Torosyan, T., and Jalaee, S. A. (2012) etc. for instance; have all verified how economic integration impact economic activities of engaged economies. Conclusions from these studies suggest that economic 'events' in one economy tend to have significant impact on economic activities in others due to growing integration. This study however, seeks to verify whether such growing integration or economic relationship between an economic powerhouse such as the US and other economies around the world continue to serve as a conduit for constrained growth for such economies or otherwise. This study subscribe to the view that significant variability exist in how specific domestic macroeconomic indicators among economies around the world respond to adverse macroeconomic conditions from a major world economy. Consequently, this study projects that economies to be tested might exhibit significant variability in how they respond to adverse macroeconomic conditions because of varied degrees of resiliency and susceptibility to economic shocks or external adverse macroeconomic conditions. This projection is supported by Moser's (1998) conceptualization of the concept of vulnerability to external stimuli. This concept posit that, the extent of vulnerability of a variable or an entity to external shock or condition depends on the degree of exposure (sensitivity) and internal capacity to ward off or contain such shock or condition (resilience). In order words, how susceptible economies to be tested are to adverse macroeconomic conditions from the U.S economy depend on these two core domestic characteristics of vulnerability all things being equal.

The rest of the study is structured as follows: Section two examines adverse U.S macroeconomic conditions whose impact on other economies this study seeks to verify. Section three highlights private final consumption expenditure among selected economies and a brief account on industrial productivity across such economies. Section four initiates the process of estimating effects of adverse U.S macroeconomic conditions on domestic conditions among stated economies by stating the key variables and data source used in this study; the section also introduces econometric model employed in the estimation. Section five provides empirical results of the estimation process, examination and discussions of the results, conclusions and policy implications of the results.

\section{Estimating Adverse US Macroeconomic Conditions}

To estimate how specific macroeconomic variables associated with selected advanced economies around the world respond to adverse macroeconomic conditions emanating from the US economy, this section discusses the three main adverse macroeconomic conditions to be tested in the study. The three include economic policy uncertainty, macroeconomic uncertainty and inflation expectations. The goal is to verify the extent to which each of these macroeconomic conditions influence industrial productivity and private final consumption expenditure dynamics characterizing selected economies. In the following analysis, each adverse macroeconomic condition is defined and discussed separately to capture key features and how it might exert projected influence on economic variables in treatment. The following provide succinct discussions on these macroeconomic parameters.

\subsection{Economic Policy Uncertainty}

Empirical studies over the years have been confronted with the challenge of quantifying economic uncertainty as perceived by policy makers and the average consumer in order to estimate how the condition ultimately impact economic activity. Legion of studies that have estimated the effect of the condition on key economic variables have resorted to the use of proxies based on stock market volatility derived from models such as the GARCH, and others from actual surveys etc. In this study however, we employ economic policy uncertainty variable (Hereafter EPU) developed by Baker et al. (2012). This uncertainty parameter measures uncertainty inherent in policy actions by key decision makers; and the potential economic effects of such actions or inactions. This form 
of uncertainty about the action or the inaction among policy makers could be monetary policy, fiscal policy etc. This index is modeled using newspaper coverage of policy-related economic uncertainty, and variability in professional expectations or forecast of key economic indicators. It is however, cogent to point out that this policy uncertainty parameter is to some extent, related to general economic uncertainty which might characterize an economy as a whole; however, the distinction is important because it captures only the policy related component of general economic uncertainty. This study, thus, investigate whether policy-related uncertainty in the U.S, as quantified by methodology employed by Baker et al. (2012), has statistically verifiable impact on industrial productivity and private final consumption expenditure dynamics among selected economies around the world.

\subsection{Macroeconomic Volatility}

Unlike the policy related form of economic uncertainty discussed above, macroeconomic volatility/uncertainty variable in this context is modeled to capture an overall macroeconomic variability or uncertainty associated with the general economic system as perceived by the average investor on consumer. In this study for instance, proposed macroeconomic volatility variable, is meant to capture uncertainty about the entire spectrum of economic activities characterizing the US economy within a specific time frame. Compared to economic policy uncertainty parameter developed by Baker et al. (2012) however, this variable is often derived or modeled using statistical estimation process such as GARCH etc. Studies such as Byrne \& Davis (2002), Driver, Temple, and Urga (2005), Baum, Chakraborty, and Liu (2010) and Baum, Stephan, and Talavera (2008), have all employed a variant of this approach in estimating uncertainty or volatility inherent in a variable (specifically, GDP growth). Following these studies, this study employs generalized autoregressive conditional heteroscedastic (GARCH) process in estimating macroeconomic uncertainty or volatility associated with US economic activities. This is done by estimating the extent of volatility inherent in GDP growth overtime. Econometrically, Generalized arch (GARCH) function capturing volatility associated with US economic performance is modeled as follows:

$$
\sigma_{t}^{2}=\omega+\alpha \varepsilon_{t-1}^{2}+\beta \sigma_{t-1}^{2}
$$

Where $\omega$ is the constant term, $\varepsilon_{t-1}^{2}$ is the ARCH term and $\sigma_{t-1}^{2}$ is the GARCH term respectively.

Equation 1 is estimated using Stata statistical package.

\subsection{Inflation Expectations/Tendencies}

This study also tests the extent to which Inflation expectations in the U.S impact industrial productivity and private final consumption expenditure among selected economies around world. Inflation expectations or tendencies in this regard defines macroeconomic environment where economic actors either by critical assessment of available information or otherwise espouse the view of an impending significant increase in the general price levels or inflationary conditions. According to the theory of rational expectations, decisions made by economic actors or agents tend to reflect relevant available information at their disposal at any point in time. Consequently, if this proposition by rational choice theory holds, then, expectations of an impending inflationary conditions or inflationary tendency might have the potential to significantly impact industrial productivity and private final consumption expenditures all things being equal. This conclusion stems from the fact that such information will be incorporated into decision making process relating to productivity and consumption dynamics. Inflation expectations variable employed in this study is sourced directly from the Federal Reserve Economic Data from St. Louis Fed database.

\section{Private Final Consumption}

\subsection{Private Final Consumption Expenditure Conditions among Selected Economies}

Private final consumption expenditure (hereafter PFCE), as modeled in this study captures consumption expenditures occurring in selected economies with the exception of those made directly by the government. We project that unlike expenditures made by government which might not reflection prevailing macroeconomic dynamics because of potential for political motivations, private final consumption expenditures will reflects variability in prevailing or projected macroeconomic conditions. This section employs graphical approach in analyzing dynamics of private final consumption associated with the various economies in treatment in this study. Economies in treatment include Canada, Germany, United Kingdom, France, Switzerland and Norway. This study, as highlighted earlier verifies the extent to which specific macroeconomic conditions associated with the U.S economy influence PFCE performance trend within these economies. In reviewing PFCE dynamics within each economy, this section provides only a succinct overview of PFCE performance associated with each economy in a graphical comparison. In the following illustrations, With the exception of Sweden, all graphical 
illustrations are based on quarterly data from 1980 to 2013. Few missing data points for Sweden will be treated accordingly using necessary tools during the empirical estimation process. The following collage of graphs illustrates quarterly percentage change in private final expenditure trends within the six economies to be tested in this study.
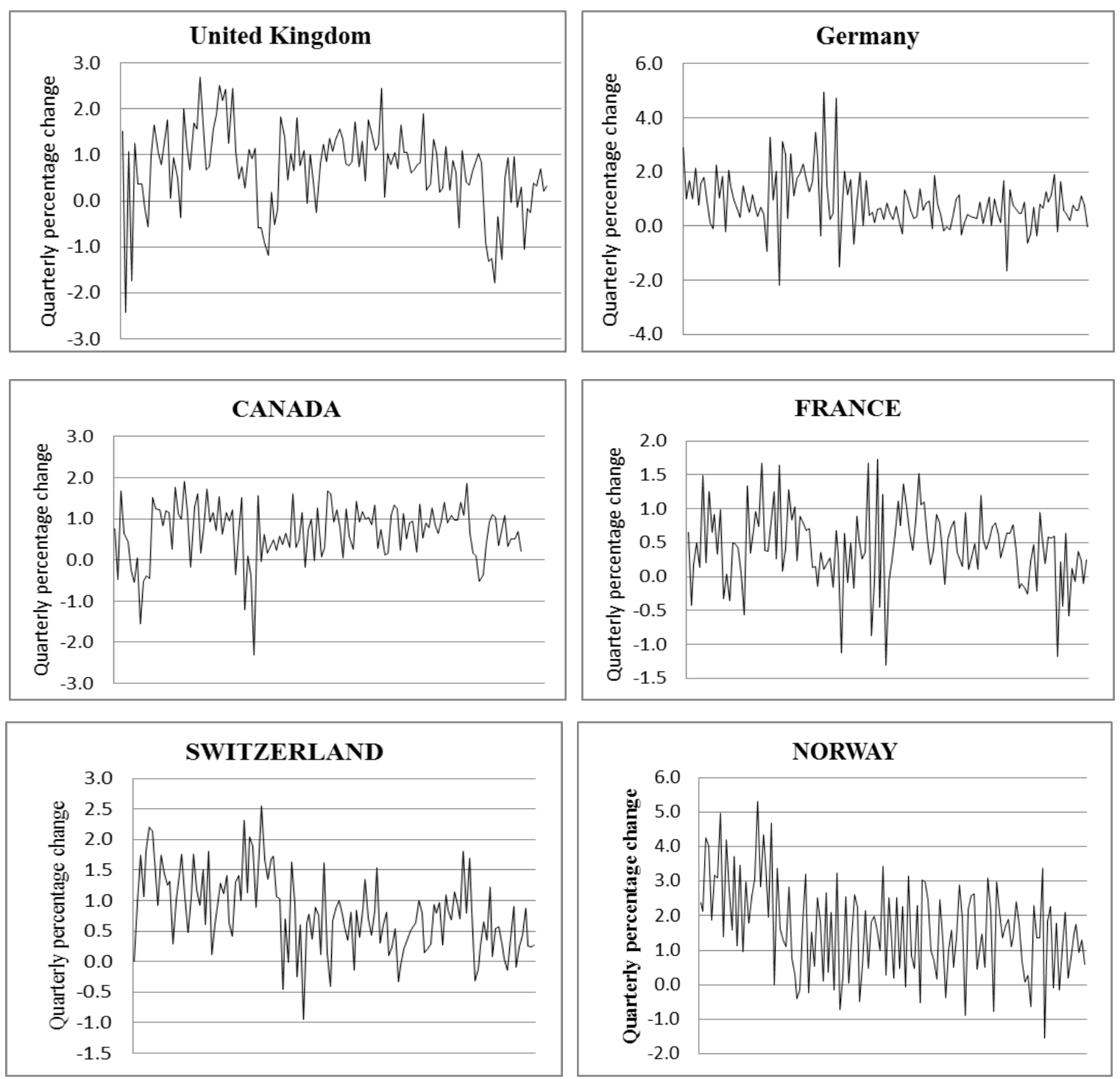

Figure 1. Private final consumption among selected economies

Critical examination of the above graphs suggests significant variability in private final consumption expenditure within the six economies employed in this study. The key question however, is the extent to which such significant fluctuations could be attributed to adverse external macroeconomic conditions emanating from the United States; the world's dominant economy. This analysis is conducted holding constant, other country specific factors or conditions which might also influence variability in private final consumption expenditures illustrated above.

\subsection{Industrial Productivity Performance among Selected Economies}

Industrial productivity is another key measure of domestic economic activity. To estimate the extent to which modeled adverse external macroeconomic conditions impact economic activities within selected economies around the world, this study also verifies the effects of such conditions on industrial productivity among economies in treatment in our verification of the economic contagion effect. The following graphical representations illustrate quarterly percentage change in industrial productivity among selected economies. It 
shows varied industrial productivity growth rates with a sharp decline in industrial productivity activities within economies such as Germany, UK, France and Canada coinciding with the recent global recession triggered by the Sub-prime mortgage crisis from the U.S. Thus, to some extent, it could be argued that adverse macroeconomic conditions such as the U.S mortgage crisis had some significant impact on domestic economic activities among economies in question. Empirical examination of the relationship to be performed in the later part of the study is thus meant to further verify this projected cross-border contagion effect of macroeconomic conditions.
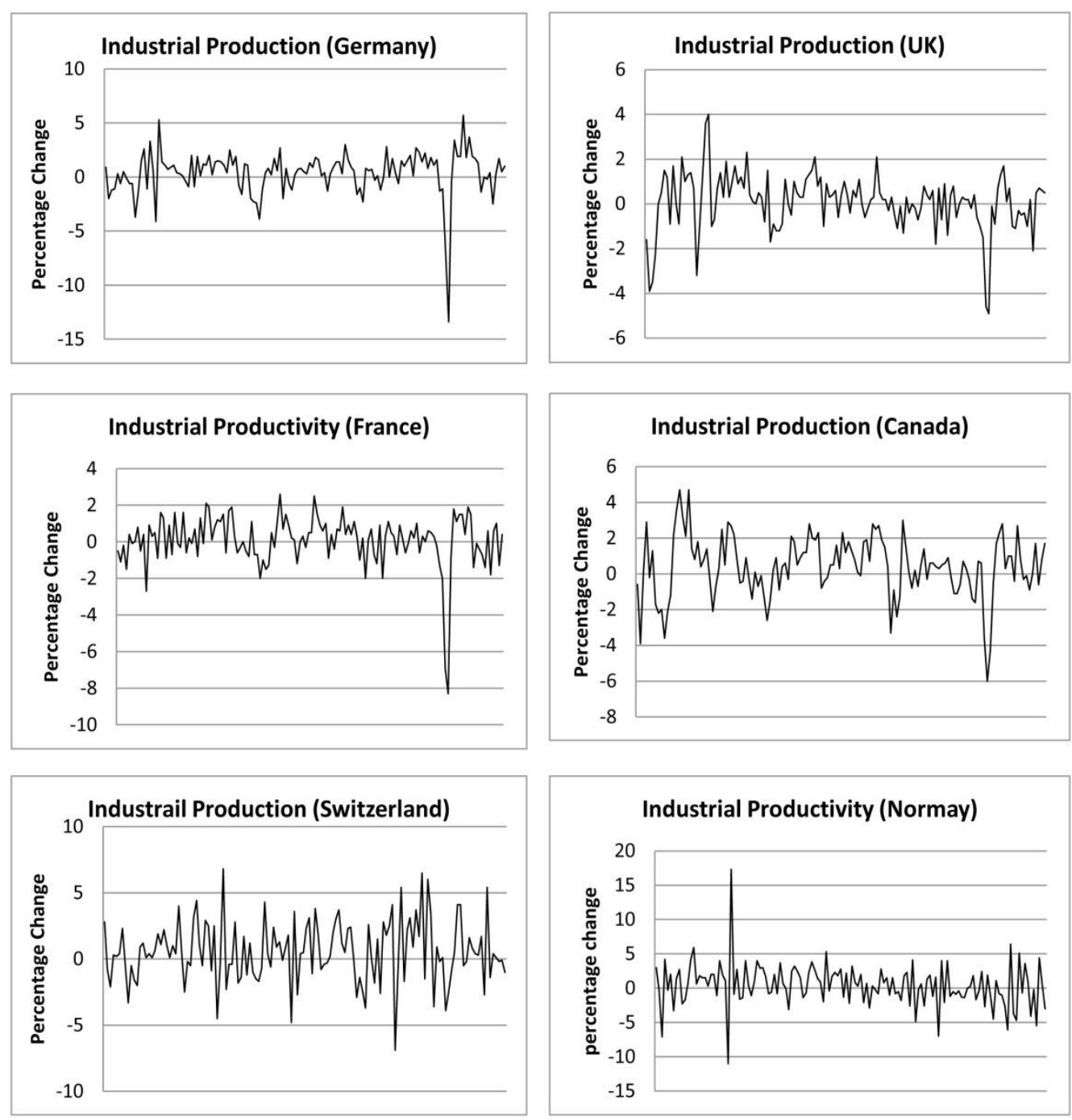

Figure 2. Industrial productivity conditions among selected economies

\section{Macroeconomic Conditions and Economic Indicators: A Brief Overview}

The literature on the effects of macroeconomic conditions on core economic indicators among economies around the world, showcase plethora of empirical studies with varied conclusions. These studies however, are dominated by those focusing on the extent to which adverse economic conditions such macroeconomic uncertainty, inflation expectations, stock market volatility and other macroeconomic shocks impact economic activities or specific macroeconomic variables within an economy. Studies such as Imtiaz and Qayyum, Abdul (2008) and (2009), Shinada (2008) and Liping et al. (2010) have verified similar relationships; by focusing on how uncertainty associated with economic activity influence investment growth within an economy. Liping et al. (2010), in their study for instance, found significant negative relationship between uncertainty and investment performance among Chinese listed companies; a conclusion which is consistent with earlier conclusion by Imtiaz and Qayyum, Abdul (2008) and (2009) in a similar uncertainty-investments growth nexus study. Apart from 
'within country' studies such as those mentioned, studies focusing on cross-border spillover effects of macroeconomic conditions are also not new. Studies in the finance literature for instance, present evidence suggesting that conditions in one economy could significantly perturb key financial indicators or variables in other linked economies. Studies such as Uribe and Yue (2006), Agenor et al. (2008), Mackowiak (2007) etc. illustrates how external conditions ultimately impact domestic conditions of some economies around the world. Uribe and Yue (2006), for instance, showed how US interest rate shock induces significant macroeconomic fluctuations among emerging economies around the world. Again, Agenor et al. (2008) further articulated how external shocks influence output fluctuations in the Argentine economy. Additionally, Mackowiak (2007) also showed that U.S. monetary policy shocks affect interest rates and exchange rate among emerging markets. These conclusions to some degree, lend credence to a form of the contagion effect this study seeks to further explore; by focusing on how specific macroeconomic conditions associated with the U.S economy influence industrial productivity and private consumptions expenditures among key advanced economies around the world.

The examination process involves estimating how spillover effect of macroeconomic indexes such as economic policy uncertainty etc. prevailing in the United States influence stated macroeconomic indicators among selected economies. This study's review of existing literature suggest that, although there is a general perception that macroeconomic condition in the U.S ultimately impact economies around the world, studies focusing on the relationship tend to be few and far between; we also found that there are no empirical studies in the literature focusing on the relationship in question using specific indicators being tested in this study.

\section{Estimating Impact of Spillover Effects of Adverse U.S. Macroeconomic Conditions}

This study projects that modeled macroeconomic conditions (Economic policy uncertainty, Macroeconomic Uncertainty and Inflationary expectations conditions) could have significant impact on both industrial productivity and private consumption expenditure dynamics among major advance economies around the world because of growing global economic integration. However, differences in domestic economic capacities based on degree of vulnerability to external economic shock, is further projected to allow for significant variations in how each economic indicator within selected economies respond to modeled adverse macroeconomic conditions. This study consequently, test for the effects of stated adverse macroeconomic conditions on industrial productivity and private consumption expenditure (the highest contributor to GDP growth) among selected economies around the world using Seemingly Unrelated Regression model (SUR).

\subsection{Research Methodology and Data}

This study utilizes data published by FRED (Federal Reserve Economic Data of St. Louis FED). Data sets used are made up of quarterly time series spanning the year 1980 to 2013. Key variables sourced from this database include U.S economic policy uncertainty $(E P U)$, macroeconomic uncertainty associated with the U.S economy $(M E U)$ - econometrically derived, Inflation expectations in the U.S (InfE), Industrial Productivity (IndPr) and final private consumption expenditures $(P C E)$ associated with selected advanced economies around the world. In testing for the extent to which stated macroeconomic conditions influence two key macroeconomic variables among listed economies, this study, as already indicated, employs Seemingly Unrelated Regression Model (SUR) in verifying dynamic relationships between key dependent and explanatory variables. The rational for the choice of this estimation model is captured in the following section.

\section{Econometric Model Specification}

\subsection{SUR Estimation}

This study opted for SUR method in its verification of aforementioned dynamic relationships because of the potential for correlated error terms between specified macroeconomic conditions and variables being tested in a two equation systems. SUR procedure which hinges on the assumption that the error terms of a given system of regression equations are correlated stand out as a good fit for tests being conducted in this study. This study employs a version of seemingly unrelated regression (SUR) model developed by Zellner, (1962). The modeling process involves estimating individual variable relationships that are linked together by contemporaneous cross-equation error correlation. Reviewed evidence from existing literature suggest that when errors terms between system of equations are correlated, the SUR estimator is more efficient in examining underlying relationships between such system of variables or indicators (Baltagi, 2005). Linear SUR equation developed by Zellner (1962) utilizes sets of regression equations with cross-equation parameter restrictions and correlated error terms with differing variances. In a compact form, such SUR model is given by:

$$
T_{j}=k_{j} \delta_{j}+e_{j}, j=1, \ldots m,
$$

with 


$$
E\left[\mathrm{e}_{i} \mathrm{e}_{j} \cdot\right]=\left\{\begin{array}{l}
\sigma_{i j} I(i \neq j) \\
\sigma_{i}^{2} I(i=j)
\end{array}\right.
$$

Where $\mathrm{T}_{j}$ and $\mathrm{e}_{j}$ are $n \times 1$ vectors, $\mathrm{k}_{j}$ is the $n \times p_{j}$ matrix of rank $P_{j}$, and $\delta_{j}$ is a $P_{j}$ dimensional coefficient vector. Equation (2) is modeled to have different independent variables and error term variances; and error terms between the equations are permitted to correlate. To estimate effects of modeled independent macroeconomic conditions (variables) on specified dependent variables via the SUR method, this study first verifies stationary conditions associated with the various macroeconomic conditions or variables employed in the study via uni-variate stationary condition analysis.

\subsubsection{Uni-Variate Stationary Condition Analysis}

Univariate analysis examines specific stationary condition features associated with individual variables to be tested in the study. Time series data employed are tested for stationary conditions or otherwise. To do so, an optimum lag order for the estimation process is first determined using all the three optimum lag order estimation procedures; i.e. Akaike Information Criterion (AIC), HQIC, and SBIC. Our estimate based on all the three procedures suggested a lag order of (1); consequently, optimal lag order of 1 is employed in examining stationary conditions associated with various variables in treatment using both the Augmented Dickey-Fuller (1981) and the Philip-Perron (1988) unit root tests procedures. The following results illustrate stationary conditions associated with variables employed in this study.

Table 1. Stationary condition analysis

\begin{tabular}{|c|c|c|c|c|c|}
\hline \multirow[t]{2}{*}{ Variables } & \multicolumn{3}{|c|}{ Augmented Dickey-Fuller Test } & \multicolumn{2}{|c|}{ Philip-Perron Test } \\
\hline & Optimum Lag Order & Test Statistic & Results & $\mathrm{Z}(\mathrm{t})$ Statisic & Results \\
\hline $\mathrm{Meu}$ & 1 & $-4.38 * *$ & $\mathrm{I}(0)$ & $-4.28 * *$ & $\mathrm{I}(0)$ \\
\hline Ери & 1 & $-10.76^{* *}$ & $\mathrm{I}(0)$ & $-12.93 * * *$ & $\mathrm{I}(0)$ \\
\hline InfE & 1 & $-4.84 *$ & $\mathrm{I}(0)$ & $-3.940 *$ & $\mathrm{I}(0)$ \\
\hline$P C E$ (norway) & 1 & $-7.57 * * *$ & $\mathrm{I}(0)$ & $-13.17 * * *$ & $\mathrm{I}(0)$ \\
\hline$P C E(u k)$ & 1 & $-4.77 * * *$ & $\mathrm{I}(0)$ & $-7.774 * * *$ & $\mathrm{I}(0)$ \\
\hline$P C E($ france $)$ & 1 & $-6.52 * * *$ & $\mathrm{I}(0)$ & $-11.67 * * *$ & $\mathrm{I}(0)$ \\
\hline$P C E($ germany $)$ & 1 & $-8.92 * * *$ & $\mathrm{I}(0)$ & $-14.31 * * *$ & $\mathrm{I}(0)$ \\
\hline PCE(switzerland) & 1 & $-6.34 * * *$ & $\mathrm{I}(0)$ & $-9.244 * * *$ & $\mathrm{I}(0)$ \\
\hline PCE (canada) & 1 & $-5.80 * * *$ & $\mathrm{I}(0)$ & $-9.458 * * *$ & $\mathrm{I}(0)$ \\
\hline$P C E(U S A)$ & 1 & $-6.65 * * *$ & $\mathrm{I}(0)$ & $-7.788 * * *$ & $\mathrm{I}(0)$ \\
\hline
\end{tabular}

Stationary condition results reported in table 1, show that various macroeconomic conditions and variables employed in this study are stable at varied significance levels under both stationary assessment estimation procedures. With stationary conditions associated with variables in treatment verified, this study proceeds to examine core interactions between specific macroeconomic conditions in the U.S economy, and variability in industrial productivity and private consumption expenditure (only PCE results reported) associated with selected advanced economies around the world via SUR estimation process.

\section{Examining Effects of US Macroeconomic Conditions on 'Global' Industrial Productivity and Private Consumption Expenditure}

\subsection{Macroeconomic Conditions and 'Global' Private Consumption Expenditures}

\subsubsection{Economic Policy Uncertainty and 'Global' Private Consumption Expenditures}

Estimated results on how specific macroeconomic conditions associated with the U.S economy impacts productivity and consumption patterns around the globe using the SUR process are reported in table 2. In the first part of the table, reported results show that the three modeled macroeconomic conditions projected to emanate from the U.S economy tend to have varying degrees of impact on private consumption expenditure patterns within the six advanced economies employed in the study. Results for instance, suggest that economic policy uncertainty emanating from the U.S economy has no statistically significant impact on consumption 
expenditure pattern within the six advanced economies tested (viz, UK, Norway, France, Germany, Canada and Switzerland). The results suggest that this macroeconomic condition is only inimical to private consumption expenditure growth within the U.S economy itself. This outcome though unexpected, might reflect the view espoused by some that since economic policies tend to be country specific, uncertainty associated with one economy might not necessarily have widespread impact on other economies despite the potential for such phenomenon to occur.

\subsubsection{Inflation Expectations and 'Global' Private Consumption Expenditures}

Still on first part of table 2, unlike U.S economic policy uncertainty variable, this study finds that inflation expectations in the U.S economy tend to have statistically significant impact on private consumption expenditures dynamics within most of the economies tested in the study. Reported results suggest that with the exception of Norway, inflation expectations in the U.S tend to influence private consumption patterns within the other five economies tested in the study. This study finds that inflation expectations concerns in the U.S tend to have negative impact on private consumption expenditure patterns in the UK, France, and Canada; however, the same condition is found to have positive impact on private consumption expenditures in Germany and Switzerland. A critical assessment of this divergent outcome among the economies tend to point to the extent of economic integration, or how closely linked these economies are, to the U.S economy and the degree of domestic economic vulnerability to external shock. Those that are closely integrated economically tend to be negatively impacted and vice versa. The results further show that inflation expectations all things being equal is also inimical to private consumption expenditure within the U.S economy itself.

\subsubsection{Macroeconomic Uncertainty and 'Global' Private Consumption Expenditures}

Additionally, empirical results reported in Table 2, further suggest that general macroeconomic uncertainty conditions about the U.S economic growth trajectory etc., tend to only constrain private consumption expenditure growth within the UK and Canadian economies. This study finds that, apart from these two economies and within the U.S itself, growing macroeconomic uncertainty about the US economy have no statistically significant influence on private consumption expenditure conditions within the German, Norway, Switzerland and the French economies. This outcome to some extent, question growing perception that any adverse macroeconomic condition associated with a major economic power such as the U.S, ultimately impact macroeconomic conditions around the globe. This result might also reflect variability in domestic capacities and resiliency levels associated with each economy as alluded to earlier. The above analysis on how the three modeled macroeconomic conditions associated with the U.S economy influence private consumption expenditure patterns around the world, thus, suggest that adverse macroeconomic conditions in the U.S might not necessarily be inimical to varied economies around the world as often believed. Our analysis suggest that, all things being equal, the extent of economic integration and domestic economic capacities could be crucial in how effects of such adverse macroeconomic conditions will be felt among economies around the world.

Table 2. Effects of modeled macroeconomic conditions of 'global' economic performance

\begin{tabular}{|c|c|c|c|c|c|c|c|}
\hline $\begin{array}{l}\text { Private Consumption } \\
\text { Expenditure }\end{array}$ & (1) USA & (2) UK & (3) Norway & (4) France & (5) Germany & (6) Switzerland & (7) Canada \\
\hline \multirow[t]{2}{*}{$E c p U$} & $-0.00303 *$ & -0.00260 & -0.00036 & 0.00143 & -0.00059 & -0.00281 & -0.00115 \\
\hline & $(0.00144)$ & $(0.00237)$ & $(0.00390)$ & $(0.00173)$ & $(0.00336)$ & $(0.00188)$ & $(0.00185)$ \\
\hline \multirow[t]{2}{*}{ InfE } & $-0.382 * * *$ & $-0.542 * * *$ & $-0.362+$ & $-0.255^{* *}$ & $0.430^{*}$ & $0.334 * *$ & $-0.408 * * *$ \\
\hline & $(0.0800)$ & $(0.131)$ & $(0.216)$ & $(0.0958)$ & $(0.186)$ & $(0.104)$ & $(0.102)$ \\
\hline \multirow[t]{2}{*}{ Meu } & $-0.508 * * *$ & $-0.748 * * *$ & -0.266 & $-0.182+$ & -0.131 & -0.120 & $-0.331 * *$ \\
\hline & $(0.0919)$ & $(0.151)$ & $(0.248)$ & $(0.110)$ & $(0.214)$ & $(0.120)$ & $(0.118)$ \\
\hline \multirow[t]{2}{*}{ _cons } & $2.106^{* * *}$ & $2.726^{* * *}$ & $2.651 * * *$ & $1.311^{* * *}$ & -0.443 & -0.225 & $2.120 * * *$ \\
\hline & $(0.253)$ & $(0.416)$ & $(0.686)$ & $(0.304)$ & $(0.590)$ & $(0.330)$ & $(0.324)$ \\
\hline$N$ & 111 & 111 & 111 & 111 & 111 & 111 & 108 \\
\hline$R^{2}$ & 0.3432 & 0.2749 & 0.0341 & 0.0798 & 0.0516 & 0.0981 & 0.1844 \\
\hline
\end{tabular}




\begin{tabular}{|c|c|c|c|c|c|c|c|}
\hline Industrial Productivity & (1) USA & (2) UK & (3) Norway & (4) France & (5) Germany & (6) Switzerland & (7) Canada \\
\hline \multirow[t]{2}{*}{ EcpU } & -0.00193 & $-0.00557+$ & 0.00421 & -0.00304 & -0.00225 & 0.00243 & -0.00450 \\
\hline & $(0.00307)$ & $(0.00322)$ & $(0.00991)$ & $(0.00418)$ & $(0.00621)$ & $(0.00790)$ & $(0.00424)$ \\
\hline \multirow[t]{2}{*}{ InfE } & $-0.818 * * *$ & $-0.537 * *$ & 0.374 & $-0.575^{*}$ & -0.222 & -0.205 & $-0.730 * *$ \\
\hline & $(0.170)$ & $(0.178)$ & $(0.549)$ & $(0.231)$ & $(0.344)$ & $(0.438)$ & $(0.235)$ \\
\hline \multirow[t]{2}{*}{ Meu } & $-1.455 * * *$ & $-1.062 * * *$ & -0.870 & $-1.288 * * *$ & $-1.691 * * *$ & -0.620 & $-1.556 * * *$ \\
\hline & $(0.196)$ & $(0.205)$ & $(0.631)$ & $(0.266)$ & $(0.395)$ & $(0.503)$ & $(0.270)$ \\
\hline \multirow[t]{2}{*}{ _cons } & $3.699 * * *$ & $2.232 * * *$ & -0.382 & $2.430 * * *$ & $1.859+$ & 1.553 & $3.328 * * *$ \\
\hline & $(0.540)$ & $(0.565)$ & $(1.741)$ & $(0.734)$ & $(1.090)$ & $(1.389)$ & $(0.744)$ \\
\hline$N$ & 111 & 111 & 111 & 111 & 111 & 111 & 108 \\
\hline$R^{2}$ & 0.4069 & 0.2557 & 0.0265 & 0.2081 & 0.1429 & 0.0161 & 0.2841 \\
\hline
\end{tabular}

Note. Standard errors in parentheses $+p<0.10, * p<0.05, * * p<0.01, * * * p<0.001$.

\subsection{Macroeconomic Conditions and 'Global' Industrial Productivity}

\subsubsection{Economic Policy Uncertainty and 'Global' Industrial Productivity}

In terms of how industrial productivity performance within selected economies respond to modeled adverse macroeconomic conditions emanating from the U.S economy, this study again finds highly varied effects on selected economies. For instance, result estimates suggest that economic policy uncertainty in the U.S as defined by Baker et al. (2012), has no statistically significant impact on industrial productivity within selected economies across the globe. The results even suggest that the condition has no verifiable impact on industrial productivity even within the U.S economy. This outcome, is highly incompatible with what this study anticipated; in that, we expected economic policy uncertainty to at least constrain industrial production to some degree given that such uncertainty might influence decision making behavior of some investors. Whereas a case could be made with respect to other economies if one takes into consideration unique domestic macroeconomic conditions which could minimize the effect of the external condition, the same cannot be said of why this macroeconomic condition seem to have no statistically verifiable impact on U.S domestic industrial production. This study projects that further testing controlling for some key related conditions might be needed to specifically understand the underlying condition responsible for the relationship between the variables in question.

\subsubsection{Inflation Expectations and 'Global' Industrial Productivity}

Effects of inflation expectations in the US on industrial productivity within the selected economies as reported in the second part of table 2 also vary significantly as projected. Results suggest inflation expectations in the U.S ultimately constrains or have negative effects on industrial productivity in economies such as the UK, France and Canada all things being equal. The macroeconomic condition is also found to be inimical to industrial productivity within the U.S itself. Additionally, this study finds that inflation expectations from the U.S economy tend to have no within data statistical influence on industrial productivity within the German and the Swiss economies. These results does not necessarily mean that inflation expectations conditions in the U.S have no influence on economic conditions in these later economies; rather, it might reflects the extent of linkages between these economies and that of U.S, as well as differences in prevailing domestic economic conditions or policies within each economy which could make effect of the condition negligible.

\subsubsection{Macroeconomic Uncertainty and 'Global' Industrial Productivity}

According to results presented in Table 2, general macroeconomic uncertainty associated with the U.S economy tend to have negative impact on industrial productivity within the UK, France, Germany and the Canadian economies respectively. Once again, economies of Norway and Switzerland seem to be less responsive or somehow insulated from such adverse macroeconomic condition emanating from the U.S economy; test results failed to find statistically significant relationship between the two variables in the case of the two economies. These divergent results to some extent further question the general notion sometimes captured in the maxim 'when the U.S economy sneezes, world economies in general catches cold'. The case of Norway and Switzerland (in both private consumption expenditure and industrial productivity analyses) suggest that macroeconomic perturbations in the U.S economy does not necessarily influence key economic indicators within all global economies as often advanced by some. 


\subsection{Conclusions}

This study examined how specific adverse macroeconomic conditions emanating from the U.S economy influence key economic performance indicators among selected advanced economies around the world with the view of verifying the 'contagion phenomenon'. Estimated results via SUR method suggest that, the contagion phenomenon is more pronounced in some economies than others. This study for instance, finds that adverse macroeconomic conditions in the U.S tend to impact trend dynamics associated with industrial productivity and private consumption expenditures among some economies, whereas other economies seems to be insulated from such conditions. Reported results thus suggest that, despite having one of the most dominant economies around the world, macroeconomic conditions prevailing in the U.S economy might not necessarily influence domestic economic indicators among all key economies around the world as often believed. Estimated results further point to the potential that, variations in how various economies responds to such adverse external macroeconomic conditions might depend to some degree on domestic economic resiliency, and individual economy's susceptibility to such conditions. Thus, the economic contagion phenomenon exists, but the extent of such phenomenon might be more country or economy specific.

\section{References}

Agenor, P. R., Aizenman, J., \& Hoffmaister, A. W. (2008). External shocks, bank lending spreads, and output fluctuations. Review of International Economics, 16(1), 1-20.

Ahmad, I., \& Qayyum, A. (2008). Effect of government spending and macro-economic uncertainty on private investment in services sector: Evidence from Pakistan. European Journal of Economics, Finance and Administrative Sciences, (11).

Ahmad, I., \& Qayyum, A. (2009). Role of public expenditures and macroeconomic uncertainty in determining private investment in large scale manufacturing sector of Pakistan. International Research Journal of Finance and Economics, (26).

Arnold, Z., \& Andob, T. (2010). A direct Monte Carlo approach for Bayesian analysis of the seemingly unrelated regression model. Journal of Econometrics, 159(1), 33-45. http://dx.doi.org/10.1016/j.jeconom.2010.04.005

Baker, S., Bloom, N., \& Davis, S. J. (2012). Measuring economic policy uncertainty. Stanford mimeo.

Baum, C. F., Chakraborty, A., \& Liu, B. (2010). The impact of macroeconomic uncertainty on firms' changes in financial leverage. International Journal of Finance and Economics, 15, 22-30. http://dx.doi.org/10.1002/ijfe.406

Baum, C. F., Stephan, A., \& Talavera, O. (2008). The effects of uncertainty on the leverage of non-financial firms. Economic Inquiry.

Byrne, J. P., \& Davis, E. P. (2002). Investment and uncertainty in the G7. Discussion papers, National Institute of Economic Research, London.

Dickey, D., \& Fuller, W. (1981). Likelihood ratio statistics for autoregressive time series with a unit root. Econometrica, 49, 1057-1072. http://dx.doi.org/10.2307/1912517

Driver, C., Temple, P., \& Urga, G. (2005). Profitability, capacity, and uncertainty: A model of UK manufacturing investment. Oxford Economic Papers, 57(1), 120-141. http://dx.doi.org/10.1093/oep/gpi001

Kamau, N. L. (2010). The impact of regional integration on economic growth: Empirical evidence from COMESA, EAC and SADC trade blocs. American Journal of Social and Management Sciences. http://dx.doi.org/10.5251/ajsms.2010.1.2.150.163

Kannan, P., \& Kohler-Geib, F. (2009). The uncertainty channel of contagion. Policy Research Working Paper. Series 4995, The Word Bank. http://dx.doi.org/10.1596/1813-9450-4995

Liping, X., Jingwei, W., \& Yu, X. (2010). Government control, uncertainty, and investment decisions in china's listed companies. China Journal of Accounting Research, 3(1), 131-157.

Mackowiak, B. (2007). External shocks, U.S. monetary policy and macroeconomic fluctuations in emerging markets. Journal of Monetary 2512-2520. http://dx.doi.org/10.1016/j.jmoneco.2007.06.021

Moser, C. (1998). The asset vulnerability framework: Reassessing urban poverty reduction strategies. World Development, 26(1), 1-19. http://dx.doi.org/10.1016/S0305-750X(97)10015-8

Naveh, M. H., Torosyan, T., \& Jalaee S. A. (2012). Regional economic integration and its effects on economic 
growth and economic welfare. World Applied Sciences Journal, 17(10), 1349-1355.

OECD. (2014). Main economic indicators: Complete database. http://dx.doi.org/10.1787/data-00052-en

Phillips, P. C. B. (1988). Regression theory for near-integrated time series. Econometrica, 56, 1021-1043. http://dx.doi.org/10.2307/1911357

Shinada, N. (2008). Corporate investment and uncertainty: An empirical analysis. RIETI Discussion Paper Series 08-E-033.

Uribe, M., \& Yue, V. Z. (2006). Country spreads and emerging countries: Who drives whom? Journal of International Economics, 69(1), 6-36. http://dx.doi.org/10.1016/j.jinteco.2005.04.003

Zellner, A. (1962). An efficient method of estimating seemingly unrelated regressions and tests for aggregation bias. Journal of the American Statistical Association, 57, 348-368. http://dx.doi.org/10.1080/01621459.1962.10480664

\section{Copyrights}

Copyright for this article is retained by the author(s), with first publication rights granted to the journal.

This is an open-access article distributed under the terms and conditions of the Creative Commons Attribution license (http://creativecommons.org/licenses/by/3.0/). 